\title{
Teaching innovation resource in the Degree of Criminology: the debate in the classroom
}

\author{
DOI: $10.46932 / s f j d v 2 n 1-009$
}

Received in: November 1st, 2020

Accepted in: December 30th, 2020

\author{
Belén Macías Espejo \\ Professor of Criminal Law \\ University of Granada \\ Plaza de la Universidad s/n- 18071 Granada (Spain) \\ E-mail: belenm@ugr.es
}

\begin{abstract}
The work presented aims to address the technique of debate as a learning tool in the subject Criminal Law II- Criminal Law. Special Part- of the Degree in Criminology.

This, based on the idea that the use of new methodologies should be promoted in the classroom; so, to shape the debate as a formula of self-learning complements the theoretical work and favors the formative skills of dynamic practice, contributing to the development of critical capacity, in terms of parameter of logical autonomous thinking, which sponsors oral communication, cooperative work and reasoned decision-making.
\end{abstract}

Keywords: University, learning, debate, competences, oral communication, critical capacity.

\section{BY WAY OF INTRODUCTION}

Learning, from a perpetual prism, is determined with the aim of improving qualifications in the personal and social sphere. To this end, the University, as an academic institution of higher education, works in this qualifying approach with the transmission of knowledge to its students.

The area of higher education has come to question the patterns of classical training - based on a passive transmission of knowledge, focused on master classes - and now learning is based on specific competences, for the exercise of the future profession, from knowledge (knowledge) and know-how (skills) as a point of direction.

The point is that there is a necessary convergence and, therefore, the University "requires a series of changes where new methods of education must appear" (Ríos Corbacho, 2011: p. 68).

So, an authentic evolution is implemented in higher education, adapting to current demands.

This new situation, before which we find ourselves, forces, therefore, to establish transformative methodologies, abandoning the obsolete academic systems, more oriented to the transmission of knowledge than to developing capacities or competencies aimed at student learning (Suárez López, 2014) . This is why the application of other formulas, by the university teacher, are increasingly common. 
The new model requires the autonomous learning of students, under the supervision / tutoring of the university faculty responsible for the different subjects, which requires a radical change with respect to the role they play, having to rely on the use of teaching tools that, accessory to the traditional ones, permit the development of innovative pedagogical methods (López Picó, 2019).

"Experiential learning is a powerful way to address individual growth and potential" (Fatemeh Mollaei \& Hamidreza Rahnama, 2012: p. 268). Active learning, which involves students in activities that force them to reflect and put into practice the questions raised, constitutes an essential part of the training process, creating a space for motivation and inquiry.

Regarding this parameter, in order for comprehensive training to promote commitment to society, and for thought to contribute to criticism, avoiding fragility, and enhancing the bond between citizens, the University must guarantee the exercise of freedom of speech, with questioning; and for this purpose, professionals are required to be adequately prepared in values and interpersonal skills (Domingo Jaramillo, 2019).

The classrooms must be constituted "in democratic settings in which to feel, experience and experience human rights, democratic citizenship and civility, in which the pedagogy of rights must be promoted" (Pérez Serrano \& Pérez de Guzmán, 2011: p. 227).

Thus, the formation of a critical society, prepared to take on challenges, raises the capacity for deliberation, in order to give serious answers to the unresolved questions that can be traced at all times.

In this sense, since university students are due to their commitment to society, I understand that academic debate is configured as the ideal mechanism for this purpose.

\section{ON THE DEBATE AS AN ACADEMIC INSTRUMENT}

The teaching methodology, a core theme in university teaching, aims to improve learning in order to promote student autonomy.

In this line, the debate becomes a nuclear academic instrument that allows students to argue, once the theory is acquired, understanding the scope of both individual and collective thought (Carrillo García \& Nevado Castellanos, 2017).

Thus, given the need for interrelation between the University and society, the contribution of the debate is configured as an effective instrument in this sense. Rodríguez Prieto (2012) states that it is time to "claim a more active role for the university in the training of a full-time citizen who thinks for himself and acts decisively to improve his society" (p. 493) .

Along these lines, an important proliferation of classes, seminars, courses and debate tournaments has been observed ; motivating the University for an improvement of skills in oratory and reflection. 
The debate technique is a very useful tool for learning, inasmuch as it cultivates rhetoric and reasoning ability by contrasting ideas and arguments.

The debate helps to improve the oral expression of the students, promoting improvisation, imagination and initiative; and, in addition, it favours critical thinking, progress and the search for rigour and truth (Esteban García \& Ortega Gutiérrez, 2017).

The debate serves as an instrument for students to develop their research capacity, since they have to master the arguments that support their thesis ; therefore, prior and precise preparation of the interventions themselves is required.

At the same time, since this practice entails holding preparatory meetings, with the teacher's supervision, virtues such as cooperation are revealed. The debate encourages teamwork; it is not only a matter of promoting healthy competition between groups, but also of developing cooperative and solidarity strategies within them.

In short, the capacities that involve the development of the debate are prescribed as elements of extraordinary relevance for obtaining a comprehensive training of the student.

The interest is, therefore, to strengthen the critical-argumentative skills of students, through the textual genre of academic debate, in order to provide an effective opportunity for students to develop logical reasoning and critical thinking, strengthening their ability to express and give an opinion on the events that affect their environment; which , , on the other hand, comes to strengthen their self-esteem and creativity (Salazar Espinosa \& Cuña, 2018).

To this end, since the convergence process encourages the use of the competency-based approach to teaching, the debate is configured as a development tool that allows linking learning with the exercise of the profession. This means that the debate perfects the generic or transversal competences (instrumental, interpersonal and systemic) necessary and the specific competences (specific to each profession), with the aim of educating students about scientific and technical knowledge and their ability to apply them in diverse and complex contexts, integrating them with their own attitudes and values from a personal, professional and social point of view (Villa Sánchez \&Villa Leicea, 2007: 17).

In this sense, in the specific field of Criminal Science, as indicated by García-Magna and BecerraMuñoz (2011), it is necessary for students to "acquire critical awareness about the repressive nature of criminal law and its various control instruments (specific cognitive competence) and that they develop the ability to assess the criminal law reality and to detect its non-explicit purposes and secondary effects (specific attitudinal competence) "(p. 514).

In this way, the debate, discussion around a topic that must revolve around approaches of social interest, in our case, legal-criminal, is configured as an ideal tool for the acquisition of the competences 
demanded by the higher education area ; thus, at the time of forging dialogue and analytical discussion, it promotes the improvement of oral communication techniques and favours cooperative teamwork and free decision-making; this, with the active involvement of the students in their learning process.

In this sense, considering that the University has to promote the responsibility and self-demand of the students, this pedagogical technique is consolidated, in order to prepare the students for the performance of a future job position, helping them to know and know how to do; and it is that, beyond mere theoretical knowledge, the debate formulates the integration of the mental and procedural structure of each student (Poblete \&Villa, 2007).

\subsection{METHODOLOGY}

The work that is presented, presents the use of the debate technique in class, as an active tool in the learning process of students in the subject of Criminal Law II -Criminal Law. Special Part- of the Degree in Criminology at the University of Granada; which is compulsory and is taught in the first semester of the second year of the Degree in Criminology, with a total duration of 6 credits (60 hours).

This diligence will constitute one of the activities that make up the practical part of the subject, the score obtained being weighted within the percentage of the final grade of $20 \%$ - adding the remaining, as follows: $10 \%$ practical work, $70 \%$ theoretical test -.

The debates will be arranged chronologically; for this, the subject will be announced in advance, so that students can prepare their position with sufficient order and rigour. This makes it possible for participants to debate about a topic they are familiar with, because they have had the opportunity to investigate previously.

In each of these moments, the students will express themselves orally and, even, is possible that they rely on audiovisual material, in order to exchange ideas. To this end, they will adopt the role of defense or objection, based on duly accredited legal reasoning - and, always, from respect. This is essential, since sometimes in various control bodies show little skill in this regard, which may call into question the veracity of the allegations.

The debate will be led by the teacher who, at all times, will influence conflictive aspects, providing information and encouraging the participation of students; although, the intervention of the students will be, in any case voluntary, being promoted with the qualification that the practice implies in the final grade of the subject.

Depending on the number of students who wish to be part of the debate, the technique will have a specific duration. In the first place, assuming that the number of participants will be high, the debate will take place in ten sessions, at a rate of two hours per session; assuming a total of twenty contact hours. To 
this end, the issues to be raised will deal with the prescription, problems and, where appropriate, the need for reform of the current punitive system of the following aspects: 1) Reviewable permanent prison and murder; purposes of the penalty 2) Euthanasia 3) Abortion 4) Domestic violence 5) Gender violence 6) Harassment -stalking 7) Consent in crimes against sexual freedom 8) Grooming 9) Sexting 10) Burglary and crime of usurpation of housing that does not constitute dwelling.

For their part, students who do not wish to take part in the debate will be given a questionnaire to estimate the quality of the activity carried out by their classmates. The questionnaire will consist of four closed questions, with four answer alternatives. Specifically: 1) Has the debate fulfilled the expected expectations? 2) Has the debate helped you to be more critical? 3) Have you empathized with the argument of a colleague? 4) Has the debate changed your opinion in relation to the subject studied? Being the answer alternatives: 1) Yes 2) No 3) Does not know 4) Does not answer.

\begin{tabular}{|c|c|c|c|c|}
\hline $\begin{array}{c}\text { Has the debate fulfilled the } \\
\text { expected expectations? }\end{array}$ & YES & NO & NS & NC \\
\hline $\begin{array}{c}\text { Has the debate helped you } \\
\text { to be more critical? }\end{array}$ & YES & NO & NS & NC \\
\hline $\begin{array}{c}\text { Have you empathized with } \\
\text { the argument of a } \\
\text { colleague? }\end{array}$ & YES & NO & NS & NC \\
\hline $\begin{array}{c}\text { 4) Has the debate changed } \\
\text { your opinion in relation to } \\
\text { the subject studied? }\end{array}$ & YES & NO & NS & NC \\
\hline
\end{tabular}

Said form will be refined with the following open points, to be determined by the observing students:

1) What has the argument of each of your classmates contributed to you?

2) Would you propose any modification / recommendation in the presentation of your colleagues?

3) What did not surprise you about the debate?

4) In what aspect has the debate transformed your opinion in relation to the subject studied?

The technique will be completed with the deliberation of a jury, made up of five members (students), which will determine, once the debate is over, which is the winning team, assessing the following criteria: 


\begin{tabular}{|c|c|}
\hline MATERIAL ISSUES & ON FORM \\
\hline Do you answer the debate question? & Dominion and respect \\
\hline Do you use an informed line within the team? & Eye contact \\
\hline Do you use serious reasoning? & $\begin{array}{c}\text { Coherence between the verbalization of themessage } \\
\text { and its execution }\end{array}$ \\
\hline Do you consistently object to the arguments? & Balance between team members \\
\hline Do you have adequate capacity for improvisation? & Time management \\
\hline Do you answer the questions adequately? & .
\end{tabular}

On the other hand, the total student body will be able to freely make, via survey, as many comments as they deem appropriate, in relation to the suitability of the method, its contribution to learning, as well as possible improvements for the future. In particular, these are the questions to be determined once the round of debates is over:

1) Have the debates been positive to strengthen the theoretical knowledge of the subject? Why?

2) Does the debate favour critical capacity? In what sense?

3) Would you modify any aspect of the dynamics? Which?

4) Would you recommend the debate in other subjects? Why?

\subsection{PUTTING IT INTO PRACTICE IN THE CLASSROOM}

The implementation of the debate methodology in class will have three moments:

1) Explanation of the contents of the subject.

2) Debate, peer assessment questionnaire and jury resolution.

3) Analysis of the results of the questionnaires filled in by the observing students and of the jury's resolution of the previous phase; locating possible errors, in order to modify them in the future.

The first day of class, prior to the start of the debate, a training session will be held, with the aim of detailing to the students the implementation of the technique, the dynamics to follow, the voluntary nature of their participation, and encouraging them to be part active in it.

Regarding the initiation, the debate will begin once the contents of the subject have been explained by the teacher, specifically, a week after the end of the teaching of the subject, each one freely choosing the role they wish to play; students will debate about it, after writing, at home, a script to serve as a guideline in the staging.

To do this, teams of five people will be organized who, previously, as has been stated, know what position (for or against) they will defend in the debate. 
The pleading time per team will be adjusted, depending on the total teams presented; leaving a turn later, so that the colleagues who adopt the role of observer can make the indications they deem appropriate and solve the questionnaires prepared. The pertinent time will also be authorized for the jury to deliberate in consideration of arguments of substance and form, in order to choose one of the teams.

At the end of the debate period, all students enrolled in the subject will be given the survey of open questions so that they can assess, voluntarily and anonymously, if the implementation of the methodology has contributed to the improvement of their learning and if they have detected any errors or question that would have to be modified in later courses.

\subsection{RESULTS}

The plan presented is currently in the experimentation phase. Its execution is intended in the first semester of the 2021-2022 academic year, which is why conclusive data on its effectiveness are not yet available.

In this sense, the results will be evaluated once the survey form has been completed by the students, whose responses will be processed.

In any case, the application of the technique in the student's learning process is expected to be positive; as it contributes to strengthen their knowledge, through critical capacity and attentiveness, with acquisition of values and interaction guidelines in reasoned discussion, and improvement in the field of oral communication.

Professionals, duly trained, who have sufficient rationality to grant appropriate treatment in the field of criminal legal operators are needed. The debate is therefore prescribed as an effective technique in this sense, since when the student assumes an active role, he is able to propose logical reasoning, offering guidelines and proposals adequate to face reality as jurists.

\subsection{DISCUSSION}

The higher education area is a challenge for teachers, requiring them to adopt new methodologies that give rise to the convenient training-learning binomial of higher education students.

The pedagogical model that is presented, intends that the students constitute an active part of the process, encouraging participation in the classroom.

The debate organizes an attractive experience for undergraduate students and, of course, also for graduate students; having to create space in the educational field, by harmonizing the theoretical part with the practice, generating the development of competences and skills, both personal and social. 
The implementation of this system in the educational regime has been promoting positive effects, since it stimulates the interest, involvement and motivation of the students, turning the classes into a dynamic and interesting environment, offering the opportunity to encourage their self-learning.

Students, being aware that they have to address a situation, pursuing the objective of trying to convince, must study the appropriate strategy, which implies distribution of work, research of sources, consultations with expert personnel in the field ... And, in In this line, it is evident to obtain mastery of the content related to the topic being debated (Moreno Soler, 2019), stimulating critical thinking and the ability to work in a team.

It is particularly effective, since it helps you use arguments to explain your ideas, learn to listen to the opinions of others, connect thoughts with reasoning and present proposals.

Thus, while being reflective with the difficulties of the start-up, I believe that patent improvement will be obtained in the education-learning process of future jurists; therefore, due to the above, the derivations that are expected to be achieved from the implementation of the debate in the subject Criminal Law II -Criminal Law. Special Part- of the Criminology Degree of the University of Granada, are encouraging.

\section{CONCLUSIONS}

The establishment of the debate in legal studies, specified, in the assumption that it is presented, in the subject Criminal Law II -Criminal Law. Special Part- of the Degree in Criminology at the University of Granada, is determined in order to improve the performance of students; by helping to strengthen critical capacity from logical reasoning; and, hoping that the results of this technique are positive, it can be applied to other subjects of the Degree.

Starting from the basis that there is no formula to teach, the teacher can decide which methodology to use, choosing between a passive or active methodology (Gálvez Jiménez, 2019).

The traditional master lecture has an undoubted training load, although the changes to which the educational process is subjected, require an effort on the part of the teachers, perfecting the formula with other methodologies that stimulate and speed up learning. Currently, the teacher is not only required to know the subject with precision, but also to be aware of how students are studying, adapting pedagogical resources to better suit their subject (Vila Ramos, 2011). This requires time and dedication, but it reports satisfactory results in the quality of teaching and in the excellence of the students.

The training process is strengthened if the student has an active credential, so the debate is projected as an attractive tool adapted to the acquisition of knowledge, values and skills that will forge the lawyer as a specialized professional. This is, not only for those students who take part in the 
representation of the technique, but is also extended to the rest of the enrolled colleagues who decide to act as observers and / or jury, since it is they who will qualify the various parameters of the activity from a reflective analytic.

Based on the above, I understand that the debate is determined as a technique of progress, adequate for the proposed purposes, in terms of an adequate instrument to improve learning. 


\section{BIBLIOGRAPHIC REFERENCES}

Carrillo García, S. \& Nevado Castellanos, K. (2017). The academic debate as a didactic strategy for the formation of argumentative competences and the approach to scientific dialogue. Traces Faces 19.34, 8-30.

Domingo Jaramillo, C. (2019). Role play as an active learning technique in Criminology. Educational innovation in the digital society. Madrid: Dykinson, 2781-2791.

Esteban García, L. \& Ortega Gutiérrez, J. (2017). The debate as a learning tool. Debate and Learning. VIII Conference on Innovation and Teaching Research, 48-56.

Fatemeh Mollaei, M.A. \& Hamidreza Rahnama, MA. (2012). Experiential Education Contributing to Language Learning. International Journal of Humanities and Social $\quad$ Scienc, Vol. 2 No. 21, 268279.

Gálvez Jiménez, A. (2019). The visit to the penitentiary as a tool for active student learning. Educational innovation in the digital society. Madrid: Dykinson, 559-566.

García-Magna, D. \& Becerra-Muñoz, J. (2011). The visit to prison as an innovative methodology in criminal law. Communication Magazine Vivat Academia, 117E, 512- 529.

López Picó, R. (2019). Cinema and the written press as means of educational innovation in the teaching of Procedural. Law Legal Journal of Educational Research and Innovation, 19, 25-38.

Moreno Soler, V. (2019). The relevance of academic debate as an instrument in university learning. Educational innovation in the digital society. Madrid: Dykinson, 917-928.

Pérez Serrano, M. G. \& Pérez de Guzmán, M.V. (2011). To learn to live together. The conflict as an opportunity for growth. Narcea: Madrid, 1-128.

Poblete, M. \& Villa, A. (2007). Competency-based learning. A proposal for the evaluation of generic competences. Bilbao: Messenger, 1-197.

Ríos Corbacho, J.M. (2011). Teaching innovation of corporate Criminal Law through collaborative techniques and virtual learning environments in the European Higher Education Area. Legal Journal of Educational Research and Innovation, 3, 67-80.

Rodríguez Prieto, R. (2012). The debate as a teaching innovation strategy. Experiences in Philosophy of Law and Theory of Culture. UPO Innova Magazine, I, 493-503.

Salazar Espinosa, C.A. \& Cuña, A.A. (2018). Discussion activities in the learning process. Education Magazine, vol. 42, no. 2, 1-22.

Suárez López, J.M. (2014). The importance of using innovative methodologies in the teaching of Criminal Law. Annals of Law, 32, 1-32.

Vila Ramos, B. (2011). A practical proposal for teaching innovation. Teaching-learning-evaluation of Constitutional Law. InDret, 1, 1-30. 
Villa Sánchez, A. \& Villa Leicea, O. (2007). Competency-based learning and the development of the social dimension in universities. Educate, 40, 15-48. 